\title{
Contra la promesa de lo queer
}

\section{( Nicolás Cuello* (IGG/UBA/CONICET)}

Abrir espacios en los que puedan emerger estrategias teórico-críticas capaces de orientarnos colectivamente para comprender y, eventualmente, sobreponernos a los ásperos límites que encuentran nuestras prácticas políticas suele ser una tarea ardua, cuando no fuertemente resistida, porque pulsa dolorosamente sobre nuestra necesaria y esquiva relación con los efectos no dominables de nuestra imaginación sexual antagonista.

Es cierto que hoy se reconoce cada vez con más precisión la existencia de una profunda crisis en la expresión colectiva de aquella promesa de transformación radical inscripta en una serie de deseos minoritarios, alternativos y disidentes que lograron desafiar temporalmente las estructuras normativas del poder sexopolítico y de sus tecnologías de subjetivación mayoritarias. Ahora bien, nuestro desafío actual consiste en pensar dicha crisis. En este sentido, Brad Epps (2016) contextualiza la emergencia de este fracaso cuando describe el modo en que se extienden, de manera global, un conjunto de técnicas político-institucionales que operan eficazmente en la obturación de la capacidad inventiva de su energía destituyente. Pero es importante recuperar una de sus principales advertencias: la sensación de esta derrota no puede ser explicada solo por procesos de condena social en aumento, por el recrudecimiento de la persecución estatal mediante tecnologías cada vez más complejas de criminalización socio-sexual, o por el efecto de otros aparatos de control biopolíticos de anulación eugenésica de la diferencia que encarnan estas sexualidades y cuerpos impropios, sino que debemos asumir que dicha desactivación responde a nuevas formulaciones de la violencia orquestadas por una matriz multicultural del poder neoliberal global que fuerza la integración de la potencia radical de dichos deseos minoritarios protegiendo y asimilando de forma acrítica toda expresión inestable de su revulsividad, para administrar de esa manera la extensión incansable de nuevos horizontes reproductivos de control y explotación financiera de la vida.

En este contexto, contamos con el comprometido trabajo de un gran número de activistas, artistas y teóricos que se han esforzado en caracterizar la emergencia global de dicha política asimilacionista, dando cuenta de algunos aspectos específicos en los que cobra forma la compleja relación entre las tecnologías de captura neoliberal con aquellas formaciones deseantes otras.

Las denuncias en clave neobarrosa, tanto de Perlongher como de Pedro Lemebel, lograron dar cuenta de los primeros efectos de desactivación crítica de las políticas de identidad sexual, al mismo tiempo que pusieron en circulación herramientas sensibles para la emergencia de vectores de subjetivación sexual desde una perspectiva
* Nicolás Cuello es Profesor en Historia de las Artes por la Universidad Nacional de la Plata. Allí mismo cursó la Maestría en Estética y Teoría de las Artes. Es secretario de la Cátedra Libre de Políticas Sexuales en la misma institución. Se desempeña como JTP en la Universidad Nacional de las Artes. Es integrante del proyecto de investigación "Genealogías críticas de las desobediencias sexuales desde el sur" dirigido por Fernando Davis en el LABIAL (FBA-UNLP). Actualmente se desempeña como Becario Doctoral del CONICET bajo la dirección de Ana Longoni y cursa el doctorado en Ciencias Sociales en la Universidad Nacional de Buenos Aires con el proyecto "Visualidades críticas: activismos artísticos y políticas sexuales en Argentina (1997-2012)", radicado en el Instituto de Investigaciones "Gino German i" de Memorias Poiticas Feministas y Sexogenericas del Cedinci/Unsam.
Semorias Poiticas Feministas y 
geopolíticamente situada (Carvajal y Davis, 2015). El reconocimiento de la loca tercermundista y su andar deseante por una anormalidad contrahegemónica en la que raza, etnicidad y clase cobraban sentidos mucho más opacos que la ascendente transparencia de la política global gay sentaron las bases de una genealogía negativa del deseo marica cuyos horizontes pulsan hasta el día de hoy por derramarse del sosiego de la aceptación, del blanqueamiento de su historia y de la comercialización de su irreverencia antinormativa.

En otra escala, pero de igual importancia, existe una emergente caracterización de fenómenos macropolíticos en los que se desenvuelven las tecnologías coloniales de cooptación, políticas públicas de integración simulada y otros sistemas a gran escala en los que se utilizan de forma instrumental las demandas y reivindicaciones de las poblaciones LGBT con el fin de justificar la profundización de políticas liberales y conservadoras, que reproducen las condiciones de posibilidad de este capitalismo voraz. El surgimiento de culturas globales homonormadas, que refieren a la construcción cultural de sujetos gay desmovilizados, privatizados y despolitizados que desactivan deliberadamente el registro de las marcas disonantes de su diferencia (Duggan, 2003), se suma a la identificación del homonacionalismo (Puar, 2007) como un fenómeno de la política actual que describe el tipo de utilitarismo xenofóbico y conservador que se hace de las vidas LGBT para la construcción criminalizante de ciertos ensamblajes específicos donde se intersecan identidad sexual, de género, racial, clase social y nacionalidad al servicio del sostenimiento de las fronteras militarizadas de la imaginación estatal. A su vez, en este mismo sentido, el término pinkwashing ha sido una herramienta innovadora utilizada principalmente por activistas de medio oriente, israelitas y palestin"s, para denunciar con especificidad el uso propagandístico de políticas públicas, discursos mediáticos, térmicas afectivas y producciones visuales que trabajan afirmando positivamente la vida de las personas LGBT garantizando su identidad, su seguridad, y sus consumos, lavando las culpas o enmascarando el despliegue de políticas capitalista de carácter imperial que trabajan en la expansión del dominio cultural, la islamofobia y el racismo.

A partir del veloz reconocimiento de dichos aportes, que logran dar cuenta de un estado de preocupación histórico e internacional en torno a la crisis política que asumen las disidencias sexuales, me interesa torcer la dirección que orienta dicho análisis, y utilizar aquella energía conflictiva de la frustración, de la pérdida y del fracaso para preguntar por otras condiciones de posibilidad que sostienen el éxito del asimilacionismo. De esta manera me interesa nombrar de forma tentativa un conjunto de prácticas sensibles, formas de representación política y dinámicas de poder presentes en los activismos de la disidencia sexual, que colaboran o reproducen el fracaso de la promesa de lo queer.

\section{Fracaso incómodo}

Existe un lugar precodificado, y lamentablemente demasiado accesible, en el reconocimiento del fracaso político de la protesta sexual. En él, solo reconocemos como desperfectos aquellas expresiones de desigualdad de operan desde la ficcionalización de un "afuera", que se ve potenciado por el reconocimiento diferencial de fuerzas que sostenemos con los dispositivos de control sexopolíticos con los cuales antagonizamos. Esta economía de representación, si bien diagrama una diferencia ineludible, nos desvincula de aquellas posibles formas de reterritorialización de las normas que nos asfixian, privándonos de la oportunidad de observar en el despliegue de nuestras estrategias políticas, en nuestros modos de acción colectiva, en la caracterización de 1 1*s sujet*s políticos de nuestros movimientos, así como en la construcción de aparatos 
teórico críticos y en las dinámicas de sociabilidad que estructuran las culturas públicas sexuales desde las que nos enunciamos, la reproducción de matrices de poder que reifican el estado actual del capitalismo global.

Fracasamos, es cierto. ¿Pero cómo lo hacemos? Tal como reconoce Epps (2016), existe una amplia bibliografía destinada a pensar el lugar del fracaso en las disidencias sexuales como vector de subjetivación, y sus formas de aparición como oportunidades de singularización antinormativa. Pero algunas de estas narraciones, a su vez, han logrado devenir productos de consumo masivo completamente funcionales a las economías restrictivas de las mercadotecnias del saber académico queer internacional, que precodifican paisajes y subjetividades políticas que escriben incluso contra la posibilidad de agenciar una política crítica desde las grietas que se abren con nuestras heridas. En la actualidad, entonces, podemos ver como la potencia del fracaso oscila entre los efectos de espectacularización fetichista por parte de las matrices productivas de la terapéutica neoliberal y la promesa alegre de su potencia incómoda.

Esa es la nueva dirección de la crisis como un interrogante que me interesa recuperar: ¿Cómo hacer del fracaso un nuevo mapa de oportunidades que no se clausure por la efectividad de la reconciliación forzada del bienestar capitalista? Hacer del fracaso un espacio de singularización para reconfigurar el horizonte de las disidencias sexuales, implica no solo el ejercicio crítico de inmiscuirse en aquella temporalidad extraña que propone, escapando de las retóricas emancipatorias del estoicismo de la política heterosexual, sino también incorporar la energía incómoda de sus efectos, el reflejo filoso de los límites contra los que nos enfrentamos, la frustración de nuestros errores, y la cita obligada con una ética responsable sobre 1*s otr*s que pueda emanciparse de las fronteras de lo moral. Fracasar implica pronunciar los efectos de la obturación, sentir la fuerza con la que se detiene nuestro movimiento, escuchar el ruido ensordecedor de lo que se derrumba, sentir la amargura de nuestra propia posibilidad de traición. Pero lejos de colaborar con las economías de la victimización (Ahmed, [2004] 2015) o con las ontologías espectacularizantes del shock y la frustración de la ansiedad neoliberal que vuelven rentable la pose de la pérdida, mercantilizando la melancolía, o desactivando los bajofondos del camp como una herida cristalizada, el fracaso puede devenir en una ética comprometida con la experimentación constante del límite subjetivo, como también un modo de producir conscientemente estrategias de reparación que pongan en marcha otra temporalidad utópica. A través de aquellos fracasos sin éxito, sin prensa, sin editoriales, sin exhibiciones, que solo parecieran ofrecernos la miseria de nuestra imposibilidad, puede emerger un tiempo en el que reconfigurar nuestros modos de acción politica, sobretodo posicionando nuestros cuerpos en alianza como susceptibles del equívoco, como agenciadores del daño, como artesanos de la falla: una oportunidad, por ejemplo, para desmantelar las propias formaciones del poder en nuestras prácticas políticas que replican imaginarios punitivistas, cisexistas, xenofóbicos, capacitistas, misóginos, gordofóbicos que restringen la extensión incontrolable de tantos deseos ansiosos de libertad.

\section{Futuro cruel}

En este mismo sentido, me interesa enunciar humildemente otra insistencia recurrente en el campo de la reflexión critica en torno a las disidencias sexuales: la invisibilidad desde la que operan de forma irresponsable los procesos de sustancialización normativa de lo queer, la reificación forzosa de dicha potencia política ante las economías temporales de la promesa utópica moderna o a los cercos estatalizados de la identidad, y las políticas de fetichización mercadotécnica de lo diferente. Parece mucho, pero es un mismo efecto que resulta de complejos procesos de globalización de lo queer, que 
1. Para profundizar en una crítica hacia las formas de contacto entre culturas visuales, desobediencias sexuales, feminismos e historia del arte desde América Latina, se puede consultar el trabajo del grupo de investigación “Genealogías críticas de las desobediencias sexuales desde el sur. Contraescrituras, tecnologías sexopolíticas y dispositivos de subjetivación" dirigido por Fernando Davis, radicado en la Facultad de Bellas Artes en la en la Facultad de Bellas Artes en la
Universidad Nacional de La Plata. afectan los modos de representación política de las disidencias sexuales, reemplazando la capacidad crítica de una agencia estratégica en torno a la desidentificación de los horizontes prescriptivos de la industrialización de lo identitario, por un paisaje codificado que se rige por la rostricidad exotizada de lo distinto, que se reemplaza a si mismo con la secuencialidad rítmica de las industrias culturales.

¿Cómo se convirtió lo queer en una identidad? Esta es una pregunta abierta en cuya órbita podemos encontrar la intersección histórica de muchos procesos políticos que explican como aquella operación histórica de contraproductividad táctica en torno a la injuria sexual se ha convertido actualmente en un nicho cada vez más atractivo para la voracidad del capitalismo cognitivo. Sin duda, algunos de los procesos de reestructuración macropolítica del neoliberalismo que nombramos anteriormente, y el éxito de proyectos de reinvindicación civil que reducen la imaginación sexopolítica al territorio de la monogamia, el matrimonio y la familia, así como al servicio militar, el individualismo, la competitividad, el lucro económico y el atractivo corporal (Epps, 2016), constituyen las condiciones de posibilidad de dicho fenómeno. Pero, nuevamente, me interesa direccionar este interrogante hacia el interior de las economías de representación con las que se articulan los repertorios de nuestras protestas sexuales.

El viraje a partir del cual lo queer y las disidencias sexuales pasan de ser modos de (des)hacer estratégicamente las condiciones de legibilidad autoritarias a la que deben responder cuerpos, deseos y prácticas sexuales no normativas, a sistemas de inteligibilidad precodificados que se rigen por marcos regulatorios de proximidad moral con una verdad ficcionalmente instituida como certeza a través de la explotación simbólica de su posible abyección en el mercado de la política internacional, restringe el potencial de transformación de una genealogía bastarda de experiencias de inestabilidad sexogenéricas cuyos contactos responden no a la prescripción de un contracanon normativo, sino a los movimientos performativos del poder mayoritario y sus flexibles fronteras que regulan la condición de lo humano.

Se ha vuelto moneda corriente, como efecto de la internacionalización acrítica de ciertos registros visuales de lo queer y de las disidencias sexuales, ${ }^{1}$ la proliferación de una nueva matriz de acción político-sexual que replica, en sus sistemas de reconocimiento, una lógica de normatividad identitaria cuyas economías culturales no distan en absoluto de la exotización antropológica del poder colonial, de la explotación subalternizadora del capacitismo, ni de la mirada absolutista de los aparatos de visión cisexistas de la modernidad. En torno a esta imposibilidad, que se vuelve presente en la proliferación acelerada de retóricas narcisistas de autoexplotación subjetiva disfrazadas de artefactos de intervención micropolíticos, se ha naturalizado lo que me gustaría identificar como la crueldad del optimismo queer. Se trata de la viralización infecciosa de una promesa normativa que reduce aquellos deseos minoritarios a tropos de figuración estético-políticos descartables, cuya temporalidad está regulada por la potencial futuridad que promete su performatividad abyecta: rasgos de identidad antinormativos abstraídos de su contexto de origen, cuyos efectos revulsivos de innovación son explotados hasta que finalmente se funcionaliza su incorporación en clave mainstream a las pantallas multiculturales del poder neoliberal, desactivando cualquier efecto de incomodidad originaria.

De esta manera, el optimismo cruel (Berlant, 2011) depositado en la identificación normativa de un sujeto político unitario de lo queer y de la disidencia sexual, produce modos de consumo de otros futuros posibles y formas de afectación con los deseos de desobediencia sexual que invisibilizan la reproducción de lógicas de explotación, silenciamiento, instrumentalización y desigualdad. Dichas figuraciones temporales de lo sexopolítico pierden la oportunidad de construir otras formas de aparición de la esperanza en las que no se actualicen las condiciones de posibilidad de los aparatos 
de producción sistemática de violencia que restringen la elaboración insumisa de nuestra libertad sexual, corporal y deseante, mientras que sí facilitan la extensión de lógicas de rufianización de la potencia descontrolada de lo minoritario.

Quizás, en la extensión tan compleja de esta adversidad en la que se desenvuelven nuestras potencias, se encuentren las condiciones de nuestra nueva oportunidad: sostenernos en la incomodidad del fracaso, abandonar el tiempo conocido de la promesa, y abrirnos a la esperanza allí donde el deseo nace del derrumbe (Jacoby, 1986). 


\section{Q Bibliografía}

》 Ahmed, S. (2015). La política cultural de las emociones. México, D.F.: Universidad Nacional Autónoma de México, Programa Universitario de Estudios de Género.

"Berlan, L. (2011). Cruel Optimism. Durham: Duke University Press.

" Carvajal, F. y Davis, F. (2015). La inflación barroca. Contra-productivizaciones neobarrocas en Néstor Perlongher y Pedro Lemebel. En XI Jornadas de Sociología „Coordenadas contemporáneas de la sociología: tiempos, cuerpos, saberes“. Buenos Aires: Facultad de Ciencias Sociales, UBA.

»Duggan, L. (2003). The Twilight of Equality: Neoliberalism, Cultural Politics, and the Attack on Democracy. Boston: Beacon Press.

»Epps, B. (2016). Los ‘fráxitos’ de la disidencia sexual en la época de la globalización neoliberal. Conferencia dictada en el seminario "Ficciones degeneradas: sexualidades disidentes en la literatura argentina y latinoamericana", dirigido por Arnes, L., y de Leone, L. Buenos Aires: Facultad de Filosofia y Letras, UBA.

"Jacoby, R. (1986). El deseo nace del derrumbe. En Crisis, 41, pp. 34-36. Buenos Aires.

"Puar, J. K. (2007). Terrorist Assemblages: Homonationalism in Queer Times. Durham: Duke University Press. 